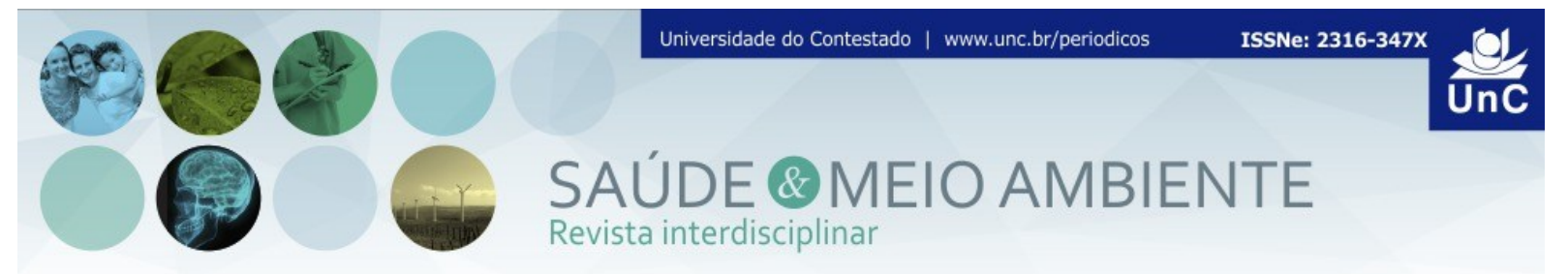

\title{
CARACTERÍSTICAS E TRATAMENTO DE FERIDAS DE USUÁRIOS ADSCRITOS NA ESTRATÉGIA DE SAÚDE DA FAMÍLIA DO BAIRRO INDUSTRIÁRIOS DE CONCÓRDIA/SC
}

\author{
Elisandra Erig Cruz ${ }^{1}$ \\ Ana Maria Cisotto Weihermann ${ }^{2}$ \\ Neide Armiliato $^{3}$
}

\begin{abstract}
RESUMO
Trata-se de um estudo do tipo quantitativo que foi desenvolvido em uma unidade de Estratégia de Saúde da Família (ESF) do município de Concórdia/SC, com objetivo de identificar as características das feridas e o tratamento instituído nos pacientes que procuraram a unidade ESF do Bairro Industriários. Foi aplicado um questionário a todos os pacientes portadores de alguma ferida que compareceram a referida unidade de saúde para fazer curativos, bem como foram realizadas visitas domiciliares para conhecer a origem do ferimento e a situação da ferida de cada paciente. A coleta de dados aconteceu no período compreendido entre março e abril de 2015. Nas visitas domiciliares a pesquisadora realizou os curativos nos pacientes. As lesões foram observadas e classificadas de acordo com o tipo, tamanho e secreções, também foi descrito o tratamento utilizado pelo paciente. Em relação ao perfil sócio demográfico a média de idade que prevaleceu foi de 15 a 35 anos (34\%) com prevalência do sexo masculino (60\%) o que justifica o alto índice de feridas acidentais $(50 \%)$ e dentro destes o fator desencadeante foi a queda (34\%). A escolaridade e a renda familiar foram baixas, uma em decorrência da outra, e muitos dos entrevistados são aposentados/pensionistas (34\%) e recebem apenas um salário mínimo. Muitos residem em casa própria e possuem carro (69\%), e residem com conjugue ou pais (81\%). Prevaleceu o uso de ácidos graxos essenciais como tratamento instituído (45\%).
\end{abstract}

Palavras-chave: Feridas. Curativos. Enfermagem.

\footnotetext{
${ }^{1}$ Acadêmica de Enfermagem da Universidade do Contestado, campus Concórdia. Santa Catarina. Brasil. E-mail: zandaec@hotmail.com

${ }^{2}$ Professora Enfermeira, Mestre em Enfermagem da Universidade do Contestado, campus Concórdia. Santa Catarina. Brasil. E-mail: anamaria@unc.br.

${ }^{3}$ Professora, Bióloga, Doutora em Biologia Celular e do Desenvolvimento da Universidade do Contestado, campus Concórdia. Santa Catarina. Brasil. E-mail: armiliato@unc.br
} 


\title{
CHARACTERISTICS AND TREATMENT OF WOUNDS OF USERS ENROLLED IN THE FAMILY HEALTH STRATEGY OF THE INDUSTRIÁRIOS NEIGHBORHOOD OF CONCÓRDIA - SC
}

\begin{abstract}
It is a study of quantitative that was developed in a unit of the Family Health Strategy (FHS) in Concórdia SC in order to identify the characteristics of the wounds and the treatment used in patients who looked for the FHS unit of the Industriários' quarter. It was applied a questionnaire to all patients with any wound that attended this unit to make bandages, and were also made home visits to know the origin of the injury and the situations of the every patient's wound. The data collection happened in the period between March and April 2015. In the home visitis the reseacher made bandages in the pacientes. The lesions were observed to identify them as type, size and secretions, the treatment was also described. In relation to the sociodemographic profile the average age that prevailed was $15-35$ years $(34 \%)$ with prevalence of males $(60 \%)$ which explains the high rate of accidental injuries $(50 \%)$ and within these the triggering factor was fall (34\%). The educational level and the family income were low, due to another, and many of the interviewees are retirees / pensioners (34\%) and receive onlyminimum wage. Many of them live in own house and own a car $(69 \%)$, and they live with spouse or parents $(81 \%)$. And prevalence of essential fatty acids as established treatment $(45 \%)$.
\end{abstract}

Keywords: Wound. Bandages. Nursing.

\section{INTRODUÇÃO}

A essência do trabalho da enfermagem é o cuidado, com isso buscamos sempre o aperfeiçoamento a fim de promover e melhorar o atendimento aos pacientes. A enfermagem busca sempre proporcionar que o indivíduo, a família e a comunidade tenham saúde o que segundo a Organização Mundial da Saúde (OMS) é um estado de completo bem-estar físico, mental e social do indivíduo (OMS, 2001).

A enfermagem cuida das pessoas em todo seu ciclo vital e nas mais variadas situações, de saúde ou doença, assim precisamos lembrar que trabalhamos com pessoas dotadas de sentimentos, vontades, aspirações e autonomia. Cuidar de feridas é um processo dinâmico, complexo e que requer uma atenção especial, o enfermeiro deve ter uma visão ampla no que se refere ao tratamento de uma ferida, é ele quem executa o curativo diariamente e está em maior contato com o paciente (MALAGUTTI; KAKIHARA, 2011).

O paciente portador de ferida segundo Malagutti e Kakihara (2011), antes de tudo, como qualquer outra pessoa, é um ser único com múltiplas necessidades, no 
entanto sua condição requer um cuidado técnico específico fundamentado por competências legais e éticas. Evidencia-se, contudo, que o cuidado é o cerne da enfermagem; está além da mera execução de procedimentos baseada em protocolos ou normas legais. Dessa forma, os cuidados realizados pelos profissionais de enfermagem ultrapassam o que está codificado, pois a qualidade da assistência não está sujeita somente a aspectos normativos, mas também à consciência profissional, formada com apoio no respeito e comprometimento com os direitos humanos. Assim pode-se afirmar que o cuidado de enfermagem é a interrelação pessoal realizada no cumprimento da lei, com empatia, autenticidade e abrangendo todas as dimensões do paciente, esteja ele com feridas ou não.

Ainda conforme Malagutti e Kakihara (2011), a prevenção de uma ferida é uma realidade difícil para o enfermeiro e outros profissionais de saúde que atendem a pacientes acamados e privados de movimento. O objetivo principal nos processos ulcerativos é a redução do período de cicatrização e prevenção de possíveis complicações, possibilitando a esses indivíduos um retorno mais rápido as suas atividades sociais e de vida diária, trazendo uma melhora na qualidade de vida dessas pessoas. Dessa maneira os futuros profissionais devem tomar consciência de que a prevenção é uma medida necessária e importante para diminuição das complicações de feridas, portanto deve-se treinar o aluno e futuro profissional a atuar também preventivamente em seu trabalho.

Segundo Balan (2012) uma ferida é representada pela interrupção da continuidade de um tecido corpóreo, em maior ou em menor extensão, causada por qualquer tipo de trauma físico, químico, mecânico ou desencadeada por uma afecção clínica, que aciona as frentes de defesa orgânica para o contra-ataque. A classificação é importante para a avaliação das feridas porque ajuda o médico e o enfermeiro a antecipar prováveis reações de acordo com o tipo de ferida. A classificação tem por base se a ferida é cirúrgica (intencional) ou traumática (acidental), ou causadas por queimaduras sendo essas consideradas feridas agudas. As crônicas são as úlceras por pressão e úlceras de membros inferiores.

Justifica-se este estudo pelo alto índice de curativos realizados pela equipe, em média de 225 curativos por mês, exigindo uma grande demanda de assistência de enfermagem e material utilizado. Assim, a avaliação de cada ferida proporcionará o conhecimento necessário, para que a equipe da ESF identifique os tipos de feridas, subsidiando assim a tomada de decisão para o melhor tratamento a ser utilizado nos pacientes que procuram a unidade. O conhecimento dos resultados deste estudo permitirão que a equipe de enfermagem identifique o que desencadeou as feridas e seus fatores de risco, para posteriormente planejar as ações de prevenção. Este estudo é importante para a universidade, para a comunidade, para a Secretaria Municipal de Saúde e para a Enfermagem porque se trata de um levantamento não realizado anteriormente que tem como objetivo proporcionar o conhecimento das características das feridas bem como de seus portadores e também os tratamentos utilizados. 


\section{MATERIAIS E MÉTODOS}

Trata-se de uma pesquisa de cunho quantitativo, que foi realizada em Concórdia, um Município de médio porte da região do Meio-Oeste de SC, no período de agosto 2014 a julho de 2015. Os dados foram coletados pela pesquisadora, através de uma entrevista utilizando-se de um questionário composto por perguntas abertas e fechadas.

Os dados somente foram coletados após a apreciação e aprovação do projeto pelo Comitê de Ética em Pesquisa Envolvendo Seres Humanos, da Universidade do Contestado, parecer $n^{\circ} 41702814.2 .0000 .0117$. Foram respeitados os aspectos éticos em relação às determinações da Resolução 466/12 do Conselho Nacional de Saúde que dispõe sobre a pesquisa envolvendo seres humanos e o Código de Ética dos Profissionais de Enfermagem. Ainda em respeito à resolução acima, a pesquisa respeitou o sigilo e anonimato dos pacientes, foi assegurado sua dignidade e respeito, bem como a autonomia e liberdade de participar ou não da pesquisa e a possibilidade de saírem da mesma se assim desejassem.

A pesquisa envolveu todos os pacientes que buscaram atendimento na unidade para realização de curativo no período da pesquisa, independente de sexo e idade. Inicialmente foi solicitada, para a realização do estudo, a autorização do Secretário de Saúde do Município e da Enfermeira responsável pela ESF Industriários.

Para cada paciente entrevistado foi apresentado o objetivo desta pesquisa, bem como o Termo de Consentimento Livre e Esclarecido. Após a aceitação por escrito dos mesmos deu-se início a coleta de dados através de uma entrevista semiestruturada ao paciente ou familiar, no período de março a abril de 2015.

Também foram feitas visitas domiciliares aos pacientes com dificuldade de locomoção, sob orientação das Agentes Comunitárias de Saúde (ACS). Nos pacientes com feridas crônicas, como as úlceras foram feitas as medidas da extensão da ferida, com fita métrica e régua e com uma sonda foi aferido a profundidade da ferida.

Após a coleta de dados os mesmos foram organizados em tabelas, comparados e analisados sob a luz do referencial teórico.

Os critérios de inclusão para a pesquisa foram:

-ser portador de ferida/s.

-ser adscrito a ESF Industriários

-aceitar participar da pesquisa. 


\section{RESULTADOS E DISCUSSÕES}

Neste capítulo apresentam-se os dados que foram coletados durante a pesquisa, bem como sua análise com base na literatura. Primeiramente foram analisados os dados sócios demográficos dos entrevistados.

A tabela 01 mostra que dos 65 pacientes entrevistados 26 são do sexo feminino (40\%), e 39 do sexo masculino (60\%). De acordo com o Instituto Brasileiro de Geografia e Estatística (IBGE) apud SEBRAE, em 2010 a população da cidade de Concórdia alcançou 68.621 habitantes, o equivalente a $1,10 \%$ da população do Estado. A distribuição populacional por sexo apontou que no município, os homens representavam $49,21 \%$ da população e as mulheres, $50,79 \%$. A Faixa etária mais frequente foi de 16 a 25 anos, 12 entrevistados correspondendo à $19 \%$, seguido de 26-35 anos, 10 entrevistados correspondendo à 15\%. A faixa etária mais jovem prevaleceu, bem como a de feridas acidentais, isto pode ter prevalecido pelo alto índice de quedas. Supõe-se que nessa faixa etária o principal meio de transporte seja motocicleta e afins, e que pessoas mais jovens trabalhem em serviços que apresentam maiores riscos, onde se utilizam de escadas e andaimes, como profissão de eletricista e na construção civil entre outros, também no manuseio de máquinas industriais ou ferramentas que possam causar acidentes, ou até mesmo envolver-se em conflitos com agressões físicas. Isso também justifica o porquê de um maior percentual de homens entrevistados com feridas do que mulheres.

Em relação à profissão, a maior prevalência foi de aposentados/pensionistas, 22 entrevistados (34\%). A renda dos inativos - aposentados e pensionistas - é fundamental para retirar famílias do limite da linha de pobreza. O salário mínimo, conforme descreve o Art. $7^{\circ}$ da Constituição da República Federativa do Brasil de 1988, tem como finalidade atender as necessidades vitais básicas dos trabalhadores e de sua família: Art. $7^{\circ}$ São direito dos trabalhadores urbanos e rurais, além de outros que visem à melhoria de sua condição social. (BRASIL, 1998, p. 13).

$\mathrm{Na}$ descrição "outros" com 21 entrevistados (33\%) incluem-se profissões como vendedor, serviços gerais, funileiro, eletricista, pedreiro, chapeador automotivo, cozinheira, auxiliar de escritório, vigilante, marceneiro e advogada.

Constata-se que grande parte dos entrevistados $46(71 \%)$ recebem menos de três salários mínimos, sendo esses considerados de baixa renda, segundo o Art. $4^{\circ}$, inciso II do Decreto ${ }^{\circ}$ 6.135, publicado em 26 de junho de 2007, que dispõe sobre o Cadastro Único para Programas Sociais do Governo Federal, estabelece que família de baixa renda é "aquela com renda familiar mensal per capita de até meio salário mínimo; ou a que possua renda familiar mensal de até três salários mínimos". Dados esses conforme tabela 1. 
Tabela 1 - Caracterização de pacientes adscritos na ESF do Bairro Industriários quanto a Sexo, Faixa Etária, Profissão e Renda Familiar.

\begin{tabular}{lll}
\hline Variável & $\mathbf{n ( 6 5 )}$ & $\mathbf{\%}(\mathbf{1 0 0})$ \\
\hline Sexo & 26 & $40 \%$ \\
$\mathrm{~F}$ & 39 & $60 \%$ \\
\hline Faixa etária (anos) & & \\
$0-5$ & 4 & $6 \%$ \\
$6-15$ & 7 & $11 \%$ \\
$16-25$ & 12 & $19 \%$ \\
$26-35$ & 10 & $15 \%$ \\
$36-45$ & 4 & $6 \%$ \\
$46-55$ & 8 & $12 \%$ \\
$56-65$ & 7 & $11 \%$ \\
$66-75$ & 6 & $9 \%$ \\
$76-85$ & 4 & $6 \%$ \\
+85 & 3 & $5 \%$ \\
\hline Profissão & & \\
Do Lar & 2 & $3 \%$ \\
Aposentado/Pensionista & 22 & $34 \%$ \\
Ajudante Produção & 6 & $9 \%$ \\
Estudante & 10 & $15 \%$ \\
Não se Aplica & 4 & $6 \%$ \\
Outros & 21 & $33 \%$ \\
\hline Renda Familiar & & $71 \%$ \\
De 1 a 3 salários mínimos & 46 & \\
Mais de 3 salários mínimos & 19 & \\
\hline
\end{tabular}

A tabela 02 representa que dos 65 pacientes entrevistados 43 (66\%) possuem moradia própria, isso se deve pelo Bairro Industriários ser um bairro antigo da cidade, muitas pessoas que moram ali adquiriram suas residências há anos onde as condições para aquisição de terrenos e residências eram melhores com valores menores. 19 pacientes entrevistados $(30 \%)$ pagam aluguel, sendo esse bairro próximo a empresa BRASIL FOODS e é muito procurado pelos funcionários da empresa. Com base em dados do Censo Demográfico, em 2010, o município possuía 23.024 domicílios, deste total, $70,8 \%$ eram próprios, $22,5 \%$ alugados, $6,5 \%$ cedidos e $0,1 \%$ em outra condição.

Além de possuir casa, 45 dos entrevistados (69\%) possuem como bem carro, pois hoje se tornou uma necessidade, como meio de transporte para deslocar-se ao trabalho, para lazer e afins. 10 pacientes (15\%) além de carro possuem motocicleta pela praticidade, menos custo de manutenção e combustível. Segundo dados do Departamento Nacional de Trânsito (DENATRAN) apud SEBRAE, no final do ano de 2012, o município possuía 51.800 veículos (1,3 habitantes por veículos sendo que a 
média nacional é de 2,9 habitantes por veículos). Já outros 10 pacientes (15\%) não possuem bem nenhum.

A tabela 2 também demonstra que 30 entrevistados (47\%) residem com conjugue, dados do IBGE censo 2010 apud SEBRAE nos mostram que em 2010 ocorreram 236 casamentos em Concórdia, 50 divórcios e 30 separações então se conclui que os casamentos ainda prevalecem sem contar as uniões estáveis onde o casamento não é oficializado. E 3 entrevistados (4\%) por opção moram sozinhos.

Analisando a escolaridade, 2 dos entrevistados (3\%) são analfabetos, ambos portadores de necessidades especiais. O que prevaleceu foi Ensino Fundamental incompleto, 34 entrevistados (53\%), muitos destes ainda estão estudando e não concluíram os estudos, e outros são idosos onde antigamente o habitual era estudar apenas 4 anos (antigo Primário). Segundo levantamento elaborado a partir dos censos demográficos disponibilizados pelo DATASUS, $12,52 \%$ da população de Concórdia possuem Ensino Fundamental Incompleto, onde a média nacional é de $13,25 \%$. Conforme tabela 2.

Tabela 2 - Caracterização de pacientes adscritos na ESF do Bairro Industriários quanto ao Tipo de Moradia, Bens, Com quem reside e Escolaridade.

\begin{tabular}{lll}
\hline Variável & $\mathbf{n ~ ( 6 5 )}$ & \% (100) \\
\hline Tipo de Moradia & 43 & $66 \%$ \\
Própria & 19 & $30 \%$ \\
Alugada & 3 & $4 \%$ \\
Cedida & & \\
\hline Bens & 43 & $66 \%$ \\
Casa & 45 & $69 \%$ \\
Carro & 10 & $15 \%$ \\
Moto & 10 & $15 \%$ \\
Não Possui & & \\
Com quem reside & 30 & $47 \%$ \\
Conjugue & 7 & $11 \%$ \\
Filho & 22 & $34 \%$ \\
Pai e Mãe & 3 & $4 \%$ \\
Irmã & 3 & $4 \%$ \\
Sozinho & & \\
Escolaridade & 2 & $3 \%$ \\
Analfabeto & 34 & $53 \%$ \\
Ensino fundamental incompleto & 4 & $6 \%$ \\
Ensino fundamental completo & 4 & $6 \%$ \\
Ensino médio incompleto & 13 & $20 \%$ \\
Ensino médio completo & 4 & $6 \%$ \\
Ensino superior completo & 4 & $6 \%$ \\
Não se Aplica & &
\end{tabular}


$\mathrm{Na}$ tabela 3 está representado como as feridas ocorreram sendo que prevaleceu o acidental com $32(50 \%)$ dos entrevistados, seguido pelo cirúrgico 18 $(27 \%)$, dentre as cirurgias identificou-se as colecistectomias, apendicectomias, herniorrafias, cantoplastias, postectomias e cesáreas. Com úlceras teve 10 dos entrevistados $(15 \%)$ e $5(8 \%)$ tiveram queimaduras. $O$ fator desencadeante que se destaca é a queda com 22 (34\%) dos entrevistados como resultado do tipo de ferida acidental. Com exsudato $23(35 \%)$ das lesões. O exsudato era serosanguinolento em 9 úlceras, a quantidade variou de escassa a grande, uma úlcera apenas com secreção purulenta em grande quantidade. Também as queimaduras apresentavam exsudato seroso em pequena quantidade e algumas escoriações. Três lesões cirúrgicas apresentavam ainda exsudato sanguinolento em pequena quantidade. Segundo Santos (2014), há uma incidência de aproximadamente 8,5 milhões de úlcera por pressão no mundo, e cerca de 12,5 milhões de úlceras venosas e 13,5 milhões de úlceras diabéticas que requerem tratamento.

Em relação ao tipo de tratamento o que prevaleceu foi com ácido graxo essencial (AGE), onde ele foi utilizado em 30 (45\%) dos entrevistados. Segundo Manhezi et al (2008), a efetividade dos AGE nos problemas relacionados às lesões de pele tem sido estudada desde 1929, quando foram realizadas as primeiras observações de lesões de pele provocadas por uma deficiência nos níveis de ácidos graxos essenciais nos alimentos que eram preparados. O curativo úmido oleoso serve como barreira protetora contra microrganismos, evita a desidratação tecidual, mantém a temperatura corpórea e diminui os traumatismos durante a substituição dos curativos, regenera os tecidos acelerando o processo de cicatrização, podendo ser usado em lesões abertas e sem infecção como no caso desta pesquisa. Nos 5 entrevistados $(8 \%)$ que apresentaram queimadura foi utilizado sulfadiazina de prata que atua contra uma grande variedade de microorganismos. 
Tabela 3 - Caracterização de pacientes adscritos na ESF do Bairro Industriários quanto ao Tipo de Ferida, Fatores desencadeantes, Características da Ferida e Tratamento utilizado.

\begin{tabular}{|c|c|c|}
\hline Variável & n (65) & $\%(100)$ \\
\hline \multicolumn{3}{|l|}{ Tipo de Ferida } \\
\hline Queimadura & 5 & $8 \%$ \\
\hline Acidental & 32 & $50 \%$ \\
\hline Cirúrgico & 18 & $27 \%$ \\
\hline Úlcera & 10 & $15 \%$ \\
\hline Fratura & 0 & $0 \%$ \\
\hline \multicolumn{3}{|l|}{ Fator Desencadeante } \\
\hline Movimentos Repetitivos & 1 & $2 \%$ \\
\hline Diabetes & 2 & $3 \%$ \\
\hline Vascular & 8 & $12 \%$ \\
\hline Queda & 22 & $34 \%$ \\
\hline Acidente de trabalho & 6 & $9 \%$ \\
\hline Outros & 26 & $40 \%$ \\
\hline \multicolumn{3}{|l|}{ Características das Feridas } \\
\hline Plana & 31 & $48 \%$ \\
\hline Profunda & 34 & $52 \%$ \\
\hline Bordas Regulares & 38 & $58 \%$ \\
\hline Bordas Irregulares & 27 & $42 \%$ \\
\hline Presença de Exsudato & 25 & $38 \%$ \\
\hline \multicolumn{3}{|l|}{ Tratamento Utilizado } \\
\hline Somente Antissepsia com Soro Fisiológico & 26 & $40 \%$ \\
\hline Acidos Graxos Essenciais & 30 & $45 \%$ \\
\hline Sulfadiazina de prata & 5 & $8 \%$ \\
\hline Hidrogel & 2 & $3 \%$ \\
\hline Hidrocolóide & 1 & $2 \%$ \\
\hline Outros (bota de unna) & 1 & $2 \%$ \\
\hline
\end{tabular}

Na tabela 4 está representado o tamanho de 08 úlceras. Dez entrevistados tinham úlceras, porém em duas dessas não foram verificada as medidas, uma vez que uma estava com a placa de hidrocolóide não podendo ser removida no momento da coleta, e outra se encontrava praticamente cicatrizada. Uma ferida tinha $27 \mathrm{~cm}$ de comprimento por 13 de largura e era plana sendo a maior; outra com $9 \mathrm{~cm}$ de comprimento por $8 \mathrm{~cm}$ de largura e $0,5 \mathrm{~cm}$ de profundidade e as outras 6 feridas com medidas variando entre 4,5 e 3,0 cm de comprimento, $3 \mathrm{~cm}$ a 0,6 de largura e de profundidade entre 0,5 a $0,2 \mathrm{~cm}$. Um dos aspectos fundamentais da avaliação de uma ferida é a sua mensuração. Esse dado é relevante, pois fornece, de maneira objetiva e sistematizada, parâmetros que indicam melhora ou piora da cicatrização da ferida. Um estudo de revisão sistemática segundo Santos (2014) realizado em Pernambuco mostrou que, na prática dos serviços de saúde, o paciente com úlceras é atendido com frequência para trocas de curativos, com sucessivas mudanças do tratamento tópico. O paciente pode conviver com essa situação que exige cuidado frequente e desgastante durante vários anos sem, no entanto obter a cicatrização da úlcera. Segundo a mesma autora resultados referentes aos produtos disponíveis para realização de curativo permitem visualizar que as unidades dispõem dos itens básicos, mas ainda não incorporaram produtos de comprovada relação custoefetivo, o que inicialmente pode repercutir em altos custos para gestão pública, mas 
ao paciente há menos troca de curativo e consequentemente menos dor, menos risco de contaminação e de infecção pelas técnicas de curativo executadas, ou de exposição ao meio ambiente.

Tabela 4 - Caracterização da mensuração das feridas de pacientes adscritos na ESF do bairro Industriários.

\begin{tabular}{llll}
\hline Úlcera & Comprimento & Largura & Profundidade \\
I & $27 \mathrm{~cm}$ & $13 \mathrm{~cm}$ & plana \\
II & $4,5 \mathrm{~cm}$ & $3 \mathrm{~cm}$ & Plana \\
III & $1,7 \mathrm{~cm}$ & $0,8 \mathrm{~cm}$ & $0,5 \mathrm{~cm}$ \\
IV & $1.5 \mathrm{~cm}$ & $0,7 \mathrm{~cm}$ & $0,5 \mathrm{~cm}$ \\
V & $1,9 \mathrm{~cm}$ & $0,6 \mathrm{~cm}$ & Plana \\
VI & $1,3 \mathrm{~cm}$ & $0,7 \mathrm{~cm}$ & $0,4 \mathrm{~cm}$ \\
VII & $3 \mathrm{~cm}$ & $1,5 \mathrm{~cm}$ & $0,2 \mathrm{~cm}$ \\
VIII & $9 \mathrm{~cm}$ & $8 \mathrm{~cm}$ & $0,5 \mathrm{~cm}$ \\
\hline
\end{tabular}

\section{CONCLUSÃO}

O estudo respondeu aos objetivos da pesquisa, onde se percebeu que houve prevalência de jovens na faixa etária de 15 a 35 anos, com predomínio do sexo masculino, o que justifica o tipo de ferida acidental predominante e como fator desencadeante a queda.

A escolaridade é baixa, apenas 4 dos entrevistados com graduação, o que reflete na renda familiar onde a maioria recebe menos de 3 salários mínimos. A grande maioria dos entrevistados reside com algum familiar seja ele o cônjuge ou os pais.

Nas feridas acidentais, que permaneceram abertas o tratamento instituído foi em sua maioria a utilização de ácidos graxos essenciais. Nas feridas onde foi necessário realizar sutura, como nas cirúrgicas foi feita a anti-sepsia com soro fisiológico.

O presente trabalho contribuiu para a identificação de clientela portadora de ferida e caracterização das lesões presentes na ESF. Os resultados obtidos sugerem que a Unidade de Saúde recebe pacientes com lesões das mais variadas etiologias. Considerando a importância do tema, e a implicação das feridas na vida dos pacientes, familiares, profissionais e instituições de saúde, sugere-se que outras pesquisas sejam realizadas para aprofundar o conhecimento, com objetivo de alcançar a melhoria da qualidade de vida dos pacientes e contribuir para o crescimento científico da enfermagem.

O portador de feridas necessita de uma assistência contínua, livre de negligência, imperícia e imprudência. Para alcançar essas qualidades no atendimento de enfermagem, é imprescindível que o enfermeiro incorpore a 
responsabilidade relativa ao seu desenvolvimento profissional e também da sua equipe. Assim, ações de educação permanente devem ser tomadas como indispensáveis na prática profissional, incentivando o aprimoramento técnico e o conhecimento e desenvolvimento das competências ético-legais, com o objetivo de prestar uma assistência especializada ao paciente com feridas.

Diante dessa realidade, acredita-se que se tornam necessárias medidas preventivas que priorizem a atuação multiprofissional, em especial do enfermeiro como agente responsável pelos processos de identificação, avaliação, tratamento e educação das pessoas com feridas.

\section{REFERÊNCIAS}

ANDRADE. M.N.B.; SEWARD, R.; MELO, J.R.C. Curativos. Revista Médica Minas Gerais, 1992.

BALAN, Marli. Guia terapêutico para tratamento de feridas. 2 ed. São Paulo: Difusão Editora, 2012.

BELO HORIZONTE. Prefeitura Municipal. Secretaria Municipal de Saúde e de Políticas Sociais. Protocolo de assistência aos portadores de feridas. Adriana Ferreira Pereira et al. Belo Horizonte, 2006.

BLANES, L. Tratamento de feridas. Disponível em:

<http://www.bapbaptista.com.>São Paulo: 2004. Acesso em: 12 maio 2015.

CONSELHO REGIONAL DE ENFERMAGEM. Câmara técnica de legislação e normas. Curitiba, 2014.

IRION, Glenn. Feridas: novas abordagens, manejo clínico e atlas em cores. Rio de Janeiro: Editora Guanabara, 2005.

MALAGUTTI, William; KAKIHARA, Cristiano Tárzia. Curativos, estomia e dermatologia: uma abordagem multiprofissional. 2.ed. São Paulo: Martinari, 2011.

MANHEZI, Andreza Cano; BACHION, Maria Márcia; PEREIRA, Ângela Lima. Utilização de ácidos graxos essenciais no tratamento de feridas. Revista Brasileira de Enfermagem, Rio de Janeiro, v. 5, n. 61, p. 620-627, 18 set. 2008.

OMS. Relatório Mundial da Saúde; saúde mental: nova concepção, nova esperança. Lisboa, 2002.

SALOMÉ, Geraldo Magela; ARBAGE, Célia Chaib. A aplicabilidade da papaína no tratamento de úlcera por pressão de calcâneo: relato de experiência. Revista Nursing, São Paulo, v. 123, n. 11, p. 364-367, 26 jun. 2007. 
SANTOS, Isabel Cristina Ramos Vieira. Caracterização do atendimento de pacientes com feridas na atenção primária. Revista Rene, Pernambuco, v. 15, n. 4, p. 15-20, julho/agosto 2014.

SEBRAE/SC. Santa Catarina em números: Estudos e Pesquisas - Cândido, Marcondes da Silva et al. Concórdia/Sebrae/SC- Florianópolis. 2013.

SILVA, Roberto Carlos Lyra da; FIGUEIREDO, Nébia Maria Almeida; MEIRELES, Isabella Barbosa. Feridas: Fundamentos e atualizações em enfermagem. 2.ed. São Paulo: Yendis Editora, 2008.

SMANIOTTO, Pedro Henrique de Souza et al. Tratamento clínico das feridas: curativos. Revista de Medicina, São Paulo, v. 89, n.3/4, p. 137-141, jul. 2010.

SMELTZER, Suzanne et al. Brunner \& Suddart: tratado de enfermagem médicocirúrgico. 11 ed. Rio de Janeiro: Guanabara Koogan, 2009.

Artigo recebido em: 28/10/2015

Artigo aprovado em: 20/04/2017 